\title{
Improving Impact Resistance of Polymer Concrete Using CNTs
}

\author{
Sherif M. Daghash ${ }^{1)}$, Eslam M. Soliman ${ }^{2), *}$, Usama F. Kandil', and Mahmoud M. Reda Taha ${ }^{4)}$
}

(Received March 15, 2016, Accepted July 10, 2016, Published online August 5, 2016)

\begin{abstract}
Polymer concrete (PC) has been favoured over Portland cement concrete when low permeability, high adhesion, and/or high durability against aggressive environments are required. In this research, a new class of PC incorporating Multi-Walled Carbon Nanotubes (MWCNTs) is introduced. Four PC mixes with different MWCNTs contents were examined. MWCNTs were carefully dispersed in epoxy resin and then mixed with the hardener and aggregate to produce PC. The impact strength of the new PC was investigated by performing low-velocity impact tests. Other mechanical properties of the new PC including compressive, flexural, and shear strengths were also characterized. Moreover, microstructural characterization using scanning electron microscope and Fourier transform infrared spectroscopy of PC incorporating MWCNTs was performed. Impact test results showed that energy absorption of PC with $1.0 \mathrm{wt} \%$ MWCNTs by weight of epoxy resin was significantly improved by $36 \%$ compared with conventional PC. Microstructural analysis demonstrated evidence that MWCNTs significantly altered the chemical structure of epoxy matrix. The changes in the microstructure lead to improvements in the impact resistance of PC, which would benefit the design of various PC structural elements.
\end{abstract}

Keywords: polymer concrete, carbon nanotubes, impact strength, microstructure, cracking.

\section{Introduction}

Concrete polymer composites were introduced to the construction industry in three types: polymer modified concrete (PMC), polymer concrete (PC) and polymer impregnated concrete (PIC). The use of PMC, PC and PIC has remarkably increased in the last 20 years. This paper is focused on PC where a thermoset polymer (e.g. epoxy, polyester) replaces cement as the adhesive matrix for concrete based on ACI Committee 548 (2009). PC has gained wide acceptance because of its relatively high strength, high bond to concrete and steel substrates, rapid setting and ease of placement. The early use of PC in the construction field was limited to repair and rapid repair applications (Wang et al. 2003). However, PC is currently used in applications with aggressive service environments such as bridge deck overlays, industrial floors,

\footnotetext{
${ }^{1)}$ Department of Civil Engineering, University of Virginia, Charlottesville, VA 22903, USA.

${ }^{2)}$ Department of Civil Engineering, Assiut University, Assiut 71516, Egypt.

*Corresponding Author;

E-mail: eslam.soliman@eng.au.edu.eg

${ }^{3)}$ Polymer Nanocomposite Center of Excellence, Egyptian Petroleum Research Institute (EPRI), Cairo 11727, Egypt.

${ }^{4)}$ Department of Civil Engineering, University of New Mexico, Albuquerque, NM 87131, USA.

Copyright $@$ The Author(s) 2016. This article is published with open access at Springerlink.com
}

utility rooms and manholes and for architectural precast panels (ACI Committee 548 2009; Radlińska et al. 2014). Because of its high damping characteristics, PC was also favored in applications with high dynamics such as machine foundations (Orak 2000). Many investigations were performed in the last two decades to modify mechanical characteristics of PC. Such investigations included replacing aggregate filler in PC by fly ash (Rebeiz and Craft 2002; Rebeiz et al. 2004), or by recycled plastic wastes (Bignozzi et al. 2000; Tawfik and Eskander 2006; Jo et al. 2007).

The impact resistance of concrete was typically improved using additives, specifically fibers, to the polymer matrix or by replacing aggregate with energy absorbent ones. Li and $\mathrm{Xu}$ (2009) improved the energy absorption capacity and deformation at failure of PC by adding basalt fibers. The dynamic modulus of elasticity and energy absorption were also improved using marble particles (Martínez-Barrera and Brostow 2010). Moreover, dispersed chopped glass and carbon fibers were used to produce fiber reinforced polymer concrete with enhanced strength, stiffness and energy absorption (Wang et al. 2013; Sett and Vipulanandan 2004). For instance, chopped carbon fibers were proved to improve the energy absorption of isophthalic polyester mortar by up to $360 \%$ (Sett and Vipulanandan 2004). Other researchers showed that carbon fibers with as low as $0.2 \%$ volume fraction were able to improve the strength and energy absorption of concrete (Xu et al. 2010).

Carbon nanotubes (CNTs) are one of the nano-scale inorganic particles utilized as additives in composites. CNTs are tabular materials made from concentrically rolled single or multiple graphite sheets. They are produced using the 
carbon arc-discharge method normally consisting of hollow carbon hexagonal networks concentrically arranged around each other and containing multiple inner chambers (Zhou and Chow 2003). CNTs were first introduced as singlewalled carbon nanotubes (SWCNTs) and proved to have superior mechanical properties, but SWCNTs showed to be significantly expensive. High-purity SWCNTs are synthesized and grown using thermal chemical vapor deposition (CVD) at a growth temperature above $700{ }^{\circ} \mathrm{C}$ (Sharma and Iqbal 2004; Ting et al. 2008). Multi-walled carbon nanotubes (MWCNTs) appeared later as a cheaper alternative form of CNTs. In CVD method MWCNTs are synthesized at a relatively low temperature of $450{ }^{\circ} \mathrm{C}$ compared to $700{ }^{\circ} \mathrm{C}$ for SWCNTs (Sharma and Iqbal 2004). Although CNTs production is a challenging process, low-cost large-scale production of MWCNTs has been reported by Huang et al. with a yield as high as $10 \mathrm{~kg} / \mathrm{h}$ using fluidized bed catalytic CVD technique (Huang et al. 2012).

MWCNTs have multiple energy and structural applications. It can be used for hydrogen storage and gas absorption (Tan et al. 2012). Moreover, MWCNTs were used to modify glass fiber reinforced polymer (GFRP) laminates to create electrically conductive networks in the matrix for structural health monitoring applications (Viets et al. 2009). MWCNTs have also been proved able to significantly improve the matrix dominated properties of GFRP (e.g. interlaminar shear strength) (Gojny et al. 2005) and to enhance the offaxis shear strength of carbon fiber reinforced polymer (CFRP) (Soliman et al. 2012a). In addition, CNTs are used to alter the impact resistance of polymer nanocomposites (Laurenzi et al. 2013) and woven fabric composite materials (Soliman et al. 2012b). It was shown that latex modified concrete with enhanced properties can be produced by incorporating CNTs in the polymer matrix during PC fabrication (Reda Taha et al. 2013). In order to enhance the bond between CNTs and polymer systems, CNTs were functionalized by chemical groups, which react with the polymer resin and hardener. Although the dispersion of CNTs in polymer matrices is a challenging process, several methods have been reported as suitable techniques for largescale dispersion of CNTs in polymer matrices including melt blending, extrusion, latex polymer technology (Choudhary and Gupta 2011; Ma and Kim 2011). In this case, the use of nanoscale imaging techniques, such as scanning electron microscope, transmission electron microscope, and X-ray photography, can be used to verify the dispersion of CNTs in the polymer matrices (Nam and Lee 2015).

Previous research has shown the potential use of CNTs as sensors for structural health monitoring applications. In particular, since CNTs are electrically conductive material, the addition of small amount, known as the percolation threshold, may alter the electrical conductivity of non-conductive polymer-based construction materials (Zamal 2011). For instance, Swain et al. (2012) reported improvement in the electrical properties of unsaturated polyester resin by incorporating allylester functionalized MWCNTs and silane functionalized MWCNTs. Furthermore, wax coated MWCNTs enhanced the electrical conductivity and improved the mechanical properties of high-density polyethylene system (Jiang and Drzal 2011). Moreover, the fatigue damage of glass fiber reinforced polymer (GFRP) composites was monitored using CNTs (Reda Taha et al. 2014).

This research investigates the ability of $\mathrm{COOH}$ functionalized MWCNTs to alter epoxy-based PC microstructure and improve PC impact resistance. The epoxy resin contains reactive epoxy groups $(\mathrm{C}-\mathrm{O}-\mathrm{C})$ at the two ends of the polymer chain. Similarly, the hardener typically contains amino groups $\left(\mathrm{NH}_{2}\right)$. It is suggested that carboxyl $(\mathrm{COOH})$ groups functionalized MWCNTs will react with epoxy to produce epoxy-MWCNTs nanocomposite that will improve the mechanical characteristics and specifically the impact resistance of $\mathrm{PC}$.

\section{Experimental Procedures}

\subsection{Materials}

In this research, PC was produced using low modulus polysulfide siloxane epoxy typically used to manufacture PC. The epoxy consists of two components; Bisphenol-based epoxy resin, and Phenol based epoxy hardener. The resin was mixed with a fine aggregate mix of crystalline silica (quartz) and bauxite-based aggregate with nominal maximum size of $4.75-\mathrm{mm}$ and a fineness modulus of 3.2. Grading of the aggregate used in producing PC is shown in Fig. 1. A similar mix is usually used in the industry to produce PC overlays. The epoxy was used as supplied to produce neat PC or was mixed with MWCNTs supplied by Cheap Tubes, Inc. The MWCNTs were produced using the catalyzed chemical vapor deposition (CCVD) method at a relatively low temperature of $450{ }^{\circ} \mathrm{C}$ with purity above $95 \mathrm{wt} \%$. In the CCVD process metallic nanoparticles such as nickel, iron, cobalt, or copper, are used to catalytically decompose gaseous carbon-containing molecules (Magrez et al. 2010). MWCNTs, used here, were functionalized by $\mathrm{COOH}$ group. The functionalization was performed using a mixture of non-organic acids producing $\mathrm{COOH}$ functional groups of $1.23 \mathrm{wt} \%$ of the MWCNTs weight. Table 1 presents the main characteristics of MWCNTs used in this research. The MWCNTs used has (20-30 nm) outer diameter and 10-30 $\mu \mathrm{m}$ length. Four PC mixes were developed and examined: neat $\mathrm{PC}$ without MWCNTs; and three other PC mixes incorporating 0.5, 1.0 and $1.5 \%$ MWCNTs by weight of the resin. The choice of these ratios is based on prior work on using MWCNTs with fiber reinforced polymer (FRP) composites (Soliman et al. $2012 b$ ). Table 2 presents the mix proportions for the PC mix. It is important to note that $1.00 \mathrm{wt} \%$ MWCNTs by weight of the resin represents $0.60 \%$ of polymer volume, based on a true density of MWCNTs of $2.1 \mathrm{~g} / \mathrm{cm}^{3}$, and thus $0.01 \%$ of concrete volume.

For the neat PC mix, the required amounts of resin and hardener were mixed together for 2-3 min using a low speed mixer, after which silica filling powder followed by the required coarse aggregate was added. Mixing continued for 2-3 min until the mixture was uniform. For the three other 


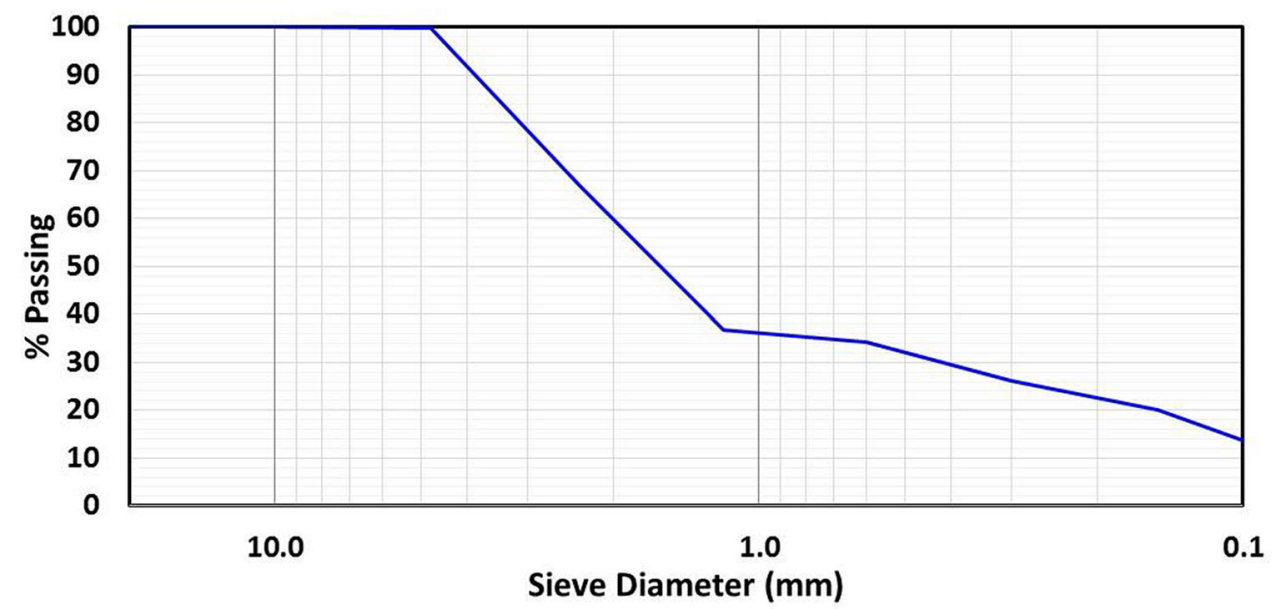

Fig. 1 Grading of aggregate used in producing PC with nominal maximum size of 4.75-mm and a fineness modulus of 3.15.

Table 1 Properties of MWCNTs (Cheaptubes, Inc.).

\begin{tabular}{c|c}
\hline Outer diameter $(\mathrm{nm})$ & $20-30$ \\
\hline Inner diameter $(\mathrm{nm})$ & $5-10$ \\
\hline MWCNTs ash $(\mathrm{wt} \%)$ & $<1.5$ \\
\hline Purity $(\%)$ & $>95$ \\
\hline Length $(\mu \mathrm{m})$ & $10-30$ \\
\hline Specific surface $\operatorname{area}\left(\mathrm{m}^{2} / \mathrm{g}\right)$ & 110 \\
\hline Bulk density $\left(\mathrm{g} / \mathrm{cm}^{3}\right)$ & 0.28 \\
\hline Electrical conductivity $(\mathrm{S} / \mathrm{cm})$ & $>100$ \\
\hline COOH content $(\mathrm{wt} \%)$ & $1.2 \%$ \\
\hline
\end{tabular}

Table 2 Mix proportions by weight of neat PC, $\mathrm{kg} / \mathrm{m}^{3}$.

\begin{tabular}{c|c|c|c}
\hline Resin & Hardener & Filler powder & Coarse aggregate \\
\hline \hline 288 & 128 & 1570 & 320 \\
\hline
\end{tabular}

mixes, MWCNTs were added to the required amount of the resin, and the mix was stirred for $2 \mathrm{~h}$ at $110^{\circ} \mathrm{C}$ using magnetic stirring. This relatively high mixing temperature was used to reduce the resin viscosity and improve the dispersion of MWCNTs. The mix was then sonicated for 2 additional hours at $65{ }^{\circ} \mathrm{C}$. During the sonication, sound waves are generated from the transducer and radiate through the liquid causing high and low pressures releasing high amount of energy and improving the dispersion of MWCNTs. The epoxy-MWCNTs nanocomposite was left to reach room temperature and then mixed with the hardener for 2-3 min. The required aggregates were added and mixing continued for 3 additional minutes until the $\mathrm{PC}$ mixture was uniform. All PC specimens were cured in air at $22{ }^{\circ} \mathrm{C}$ and $50 \%$ relative humidity for 7 days as recommended by ACI Committee 548 (2009).

\subsection{Testing Methods}

Low-velocity impact testing was performed on the four PC mixes with varying MWCNTs content. Low-velocity impact is an essential test to determine the dynamic characteristics of PC reinforced with MWCNTs. The test is relevant to the design of civil infrastructure where concrete structural elements, such as concrete slabs, are often subjected to drop of heavy weights (e.g. steel elements) during the construction operations of multi-story buildings (Algaard et al. 2005; Izatt et al. 2009). In addition, polymer concrete pipes may drop resulting in impact loading during the transportation and installation of pipelines. In other situations, the reinforced concrete girders or barriers may also be subjected to low velocity vehicles' collision (Batarlar 2013). Additionally, the flowability test was performed to judge the effect of adding MWCNTs on the flowability of the fresh polymer concrete. Furthermore, static compressive, flexural, and shear strength tests were performed, as shown in Fig. 2, to understand the effect of MWCNTs on basic mechanical properties of PC. Compressive, flexure, and shear failures were selected for evaluation as they represent the different failure modes structural PC may encounter when subjected to impact loading. Therefore, evaluating the effect of adding 


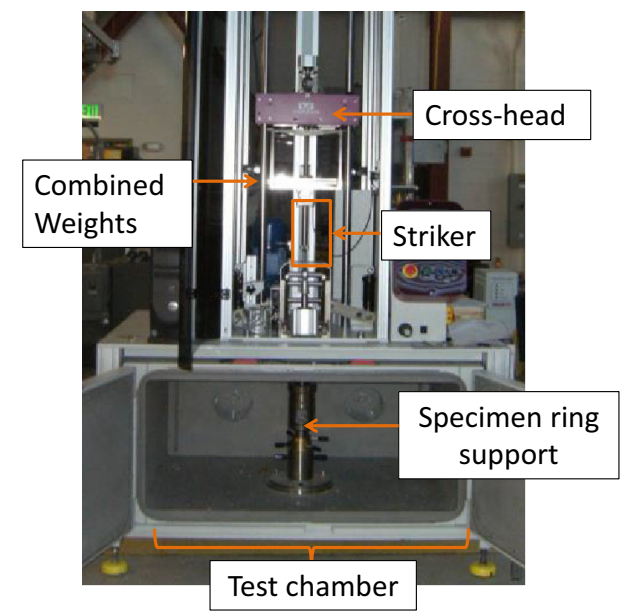

(a)

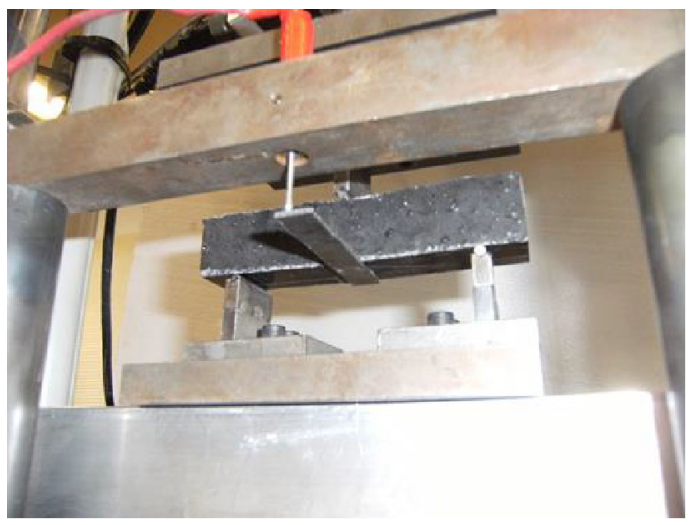

(c)

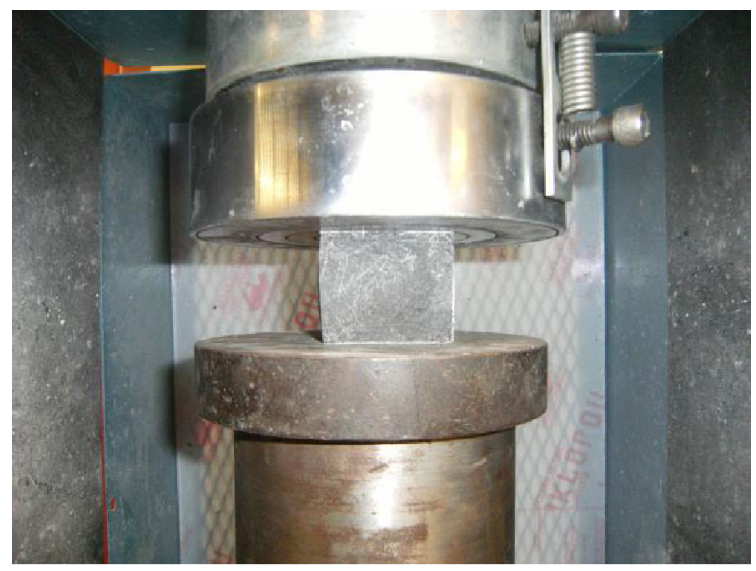

(b)

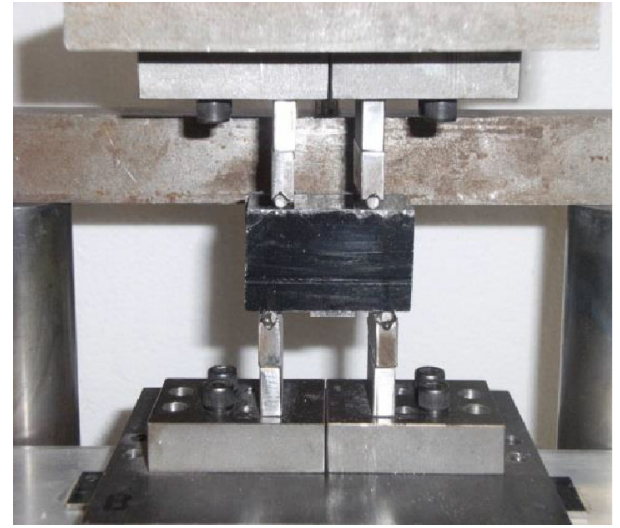

(d)

Fig. 2 Mechanical testing of PC incorporating MWCNTs a impact testing equipment, b compressive strength test, $\mathbf{c}$ flexural strength test, $\mathbf{d}$ shear strength test.

MWCNTs on the three mechanical properties would help understanding the change in the response of low-velocity impact tests. Specimens for each test, except for the flowability test as it was performed once for each mix, were produced in replicas of three for each mix. Based on the limited coefficient of variation (COV) of the test results, three replicas were found sufficient to precisely compare the mechanical properties for the different PC mixes.

\subsubsection{Flowability Test}

The test was performed according to ASTM C1437 where a flow table, a flow cone, and a test caliper were used (ASTM C1437 2009). The cones' smaller diameter was $70-\mathrm{mm}$, larger diameter was $100-\mathrm{mm}$, and the height was 50-mm. For testing, each mix was prepared and the cone was filled by fresh mix in two layers, and each layer was tamped 20 times. The cone was lifted in $4 \mathrm{~s}$ and 25 strikes were applied to the fresh specimen in $15 \mathrm{~s}$. After the 25 strikes, four perpendicular readings were taken by the test caliper. The flowability percentage was considered as the sum of the previous four readings.

\subsubsection{Impact Test}

The impact test was performed using $\mathrm{CEAST}^{\circledR} 9350$ drop tower low velocity impact tester by Instron ${ }^{\circledR}$. The test was performed by dropping a 12.7- $\mathrm{mm}$ diameter hemispherical striker carrying a total weight of $14.93 \mathrm{~kg}$ on the specimens and recording specimen response. The total weight includes a carriage weight of $4.3 \mathrm{~kg}$, a striker weight of $0.63 \mathrm{~kg}$, and $10 \mathrm{~kg}$ additional weights. The testing system is equipped to measure the time history for the striker force and incident velocity. This is achieved using a load cell attached to the striker and a laser system mounted at the specimen elevation to measure the incident velocity. In addition, the testing system is designed and instrumented according to ASTM D7136 (2007) and ISO 6603-2 (2000) standards such that the effect of inertia force is minimized. In this regard, three cautions are considered during the test. First, dynamic calibration of the striker's load cell is performed within an accuracy of $\pm 1.0 \%$. In addition, the strikers' load cell was placed as close as possible at a distance of 12-mm from the contact surfaces (e.g. striker's tip). Furthermore, $97 \%$ of the impactor mass is located above the load cell. The prisms for this test were 100mm square prisms with 20-mm thickness. During the test, the specimens were clamped by two rings attached to the test machine of outer diameter of $100-\mathrm{mm}$. $40 \mathrm{~J}$ of energy were applied on each specimen. The choice of the energy to test the specimens was done after a few trials to ensure that the energy used was enough to penetrate the neat PC specimens. Using a data acquisition system and sampling rate of $800 \mathrm{kHz}$, the 
time history of impact force $F(t)$, absorbed energy $E(t)$ and test velocity $v(t)$ were recorded using the following equations according to ASTM D7136 (2007).

$$
\begin{aligned}
& v(t)=v_{i}+g t-\int_{0}^{t} \frac{F(t)}{m} \mathrm{~d} t \\
& \delta(t)=\delta_{i}+v_{i} t+\frac{g t^{2}}{2}-\int_{0}^{t}\left(\int_{0}^{t} \frac{F(t)}{m} \mathrm{~d} t\right) \mathrm{d} t \\
& E(t)=\frac{m\left[v_{i}^{2}-v(t)^{2}\right]}{2}+m g \delta(t)
\end{aligned}
$$

where $t$ is time, $v_{i}$ is the initial velocity, $g$ is gravity, $m$ is the applied mass, $\delta(t)$ is the displacement, and $\delta_{i}$ is the initial position.

\subsubsection{Compressive Strength Test}

The compressive strength test was performed in a standard compression machine on three 50.8-mm cubes made from each mix. The cubes were tested at 7 days of age with loading rate of $6 \mathrm{kN} / \mathrm{min}$ according to ASTM C579 (2012).

\subsubsection{Flexural Strength Test}

In order to perform the flexure test, polymer concrete prisms were fabricated from each mix. The prisms dimensions were $25.4-\mathrm{mm} \times 25.4-\mathrm{mm} \times 116-\mathrm{mm}$. The prisms were tested in a three-point bending test setup at 7 days of age with a loading rate of $0.3 \mathrm{kN} / \mathrm{min}$ according to ASTM C78 (2002). The distance between the supports was 96-mm. The mid span deflection was recorded using a linear variable differential transducer (LVDT). The flexure load and displacement were performed using a servo hydraulic system and recorded using a data acquisition system with a sampling rate of $10 \mathrm{~Hz}$ for all experiments.

\subsubsection{Shear Strength Test}

The shear test was performed following the guidelines of ASTM D4475 in what is known as a short beam setup (ASTM D4475 2008). To enforce shear failure in that test, the distance between supports was limited to $32-\mathrm{mm}$ and the distance between points of loading was set at 24-mm such that the distance between each support and the adjacent point of loading "shear span" was limited to 4-mm as shown in Fig. 2 d. The prisms were tested in a four-point bending at 7 days of age. The shear test was performed using servo hydraulic system and recorded data acquisition system with sampling rate of $10 \mathrm{~Hz}$ for all experiments.

\subsection{Microstructural Characterization}

The microstructural characterization tests of epoxyMWCNTs nanocomposite were performed on specimens of neat epoxy and epoxy with $1.0 \mathrm{wt} \%$ MWCNTs to explain the improvement observed in the macroscale mechanical response of PC incorporating MWCNTs. The microstructural characterization tests included scanning electron microscope (SEM), microscopic images, and Fourier transform infrared spectroscopy (FTIR) tests. In both the SEM and FTIR, no filler powder or aggregate was used in the microstructural characterization tests while in the microscopic images all polymer concrete components are examined.

The main goal of SEM investigation is to give an insight on dispersion of CNTs in polymer matrix and the mechanical mechanism of CNTs in polymer concrete composites. The microstructural features of a fractured surface of epoxy reinforced with $1.0 \mathrm{wt} \%$ MWCNTs were investigated under SEM with a guaranteed resolution of $0.5-1.7 \mathrm{~nm}$ at $30-1 \mathrm{kV}$, respectively. In addition, $100 \times$ magnification microscopic images are presented for the PC with neat epoxy and epoxy incorporating $1.0 \%$ MWCNTs to assess the quality of mixing polymer concrete components (e.g. epoxy, aggregates, and powder).

In FTIR, samples of neat epoxy and epoxy incorporating MWCNTs were analyzed with biconical reflectance MicroFourier Transform Infrared Spectroscopy (Micro-FTIR) apparatus. The FTIR has a continuum microscope with a Globar source, XT-KBr beam splitter and a MCT-A detector over a $100 \times 100 \mu \mathrm{m}$ area with a $4-\mathrm{cm}^{-1}$ resolution. Spectra were background corrected using a reflective gold slide and converted to absorbance using the Kramers-Kronig equation as per standard FTIR analysis method (Roessler 1965).

\section{Results and Discussion}

\subsection{Impact and Mechanical Properties of PC}

Figure 3 shows the effect of MWCNTs on flowability of PC. Flowability of the fresh polymer concrete was decreased by 18,22 , and $26 \%$ with addition of $0.5,1.0$, and $1.5 \mathrm{wt} \%$ of MWCNTs, respectively. Figure 4 shows the impact forcetime history of the PC mixes. The peak force increased by $9 \%$ with adding $1.0 \mathrm{wt} \%$ MWCNTs, while decreased by 4 and $3 \%$ with adding 0.5 and $1.5 \mathrm{wt} \%$ MWCNTs, respectively. Statistical analysis using analysis of variance (ANOVA) with a $95 \%$ level of confidence showed the change in the peak force to be statistically insignificant. The addition of MWCNTs did not therefore make a significant change in the peak force. The insignificant improvement of the impact peak force might be attributed to the insignificant effect of MWCNTs on shear strength of PC as described below. On the other hand, the graphs in Fig. 4 also show that adding MWCNTs increased the residual resistance of PC after the impact event significantly. The residual resistance factor "RRF" was defined here as the ratio of the residual force to the peak force observed by the specimen. The residual force was selected at $3 \mathrm{~ms}$ to evaluate the residual capacity of the PC specimens after reaching the peak force. The RRF examines the ability of the PC specimens to remain intact and to continue carrying the load after hitting the striker. An increase in the RRF demonstrates a more ductile failure for PC specimens. An inset in Fig. 4 shows the significant improvement in the residual resistance factor of PC 


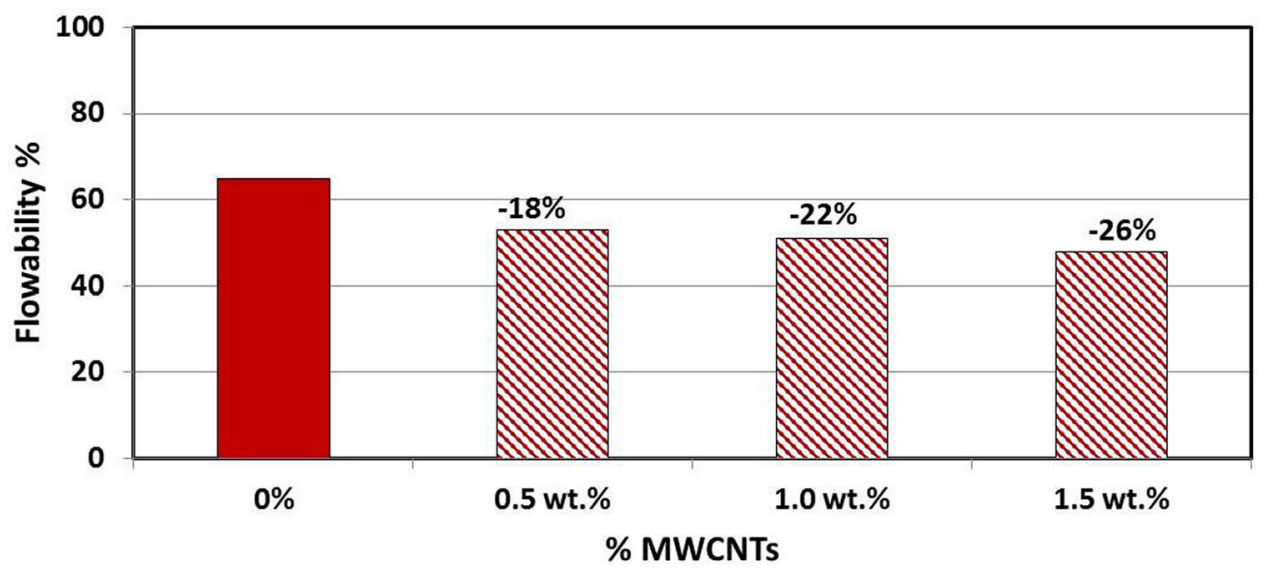

Fig. 3 Effect of MWCNTs on PC flowability. The \% presented above the bars represents the reduction of flowability compared with neat $\mathrm{PC}$ at $0 \%$.

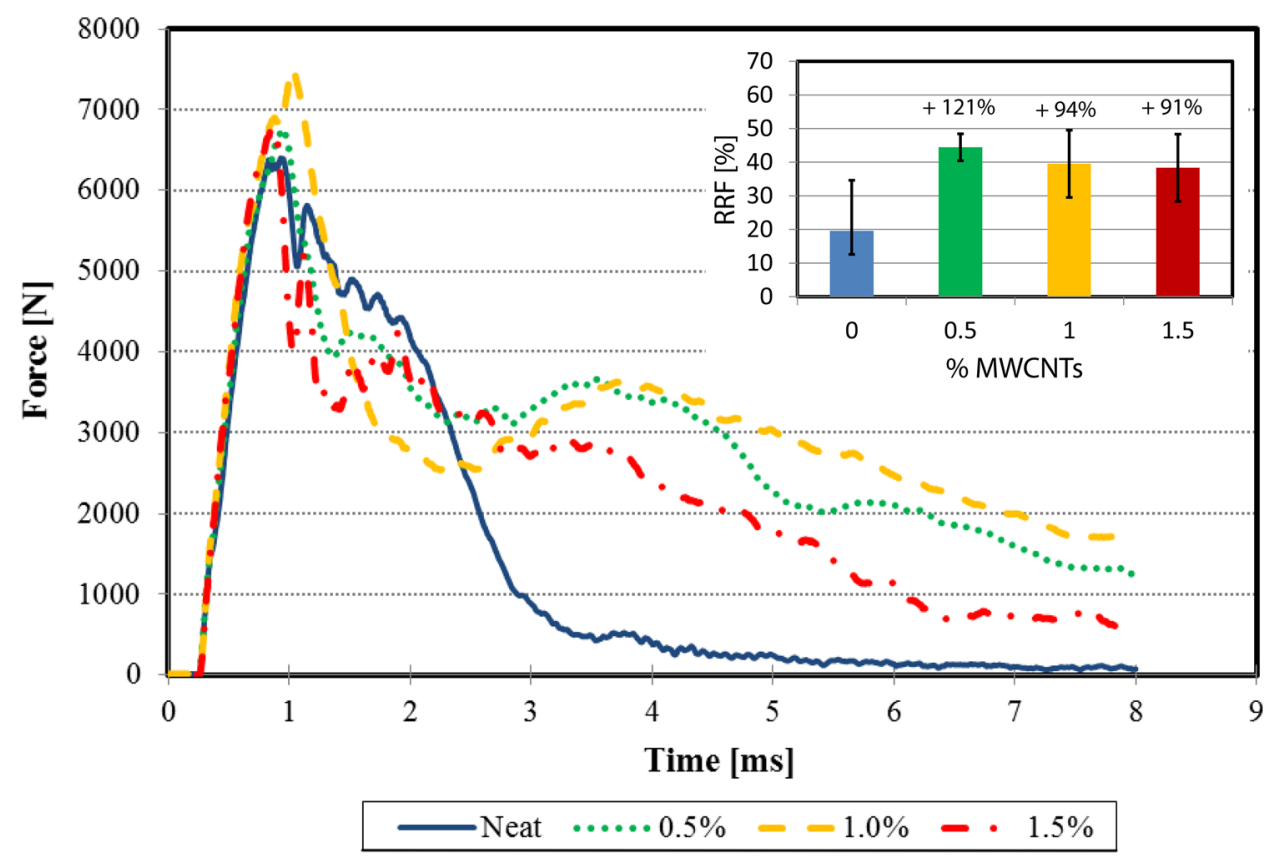

Fig. 4 Effect of MWCNTs on PC resistance to impact loads. Main figure shows force-time response of PCs with different MWCNTs contents and inset figure shows the significant increase in the residual resistance factor of PC with MWCNTs specimens reflecting the ability MWCNTs to dissipate energy in PC.

after impact of 44,39 and $38 \%$ for $0.5,1.0$ and $1.5 \mathrm{wt} \%$ MWCNTs, respectively compared with $20 \%$ for neat PC. It is obvious that MWCNTs better dissipated damage in PC due to the impact load which enabled PC with MWCNTs to have a higher residual resistance after impact compared with neat PC.

It can also be observed in Fig. 5 that the MWCNTs increased the difference between the initial velocity and the final velocity. The significant reduction of penetration velocity (i.e. slowdown of the impact striker inside the PC matrix) incorporating 0.5 and $1.0 \mathrm{wt} \%$ MWCNTs is evident in Fig. 5. The increase in the slowdown of the impact striker reflects the ability of PC incorporating MWCNTs to better dissipate the impact energy applied to the specimen compared with neat PC. That was further confirmed by observing the cracking pattern of impact specimens of $\mathrm{PC}$ incorporating MWCNTs as discussed later. The absorbed impact energy increased by 29,36 , and $19 \%$ in the case of $0.5,1.0,1.5 \mathrm{wt} \%$ MWCNTs, respectively, as shown in Table 3. Statistical analysis using Student's t-test proved that the impact energy for PC mixes 0.5 and $1.0 \mathrm{wt} \%$ MWCNTs is significantly higher than that of neat PC. No significant difference was observed for PC with $1.5 \mathrm{wt} \%$ MWCNTs. The impact tests proved that adding well dispersed and functionalized MWCNTs improved impact resistance of PC. It is evident that MWCNTs provided an energy dissipation mechanism that enables higher energy absorption than that of the conventional PC. The limited improvement in PC incorporating $1.5 \mathrm{wt} \%$ MWCNTs is attributed to the decrease in epoxy flowability and the difficulty to disperse this relatively high amount of MWCNTs in the epoxy resin as further discussed below. 


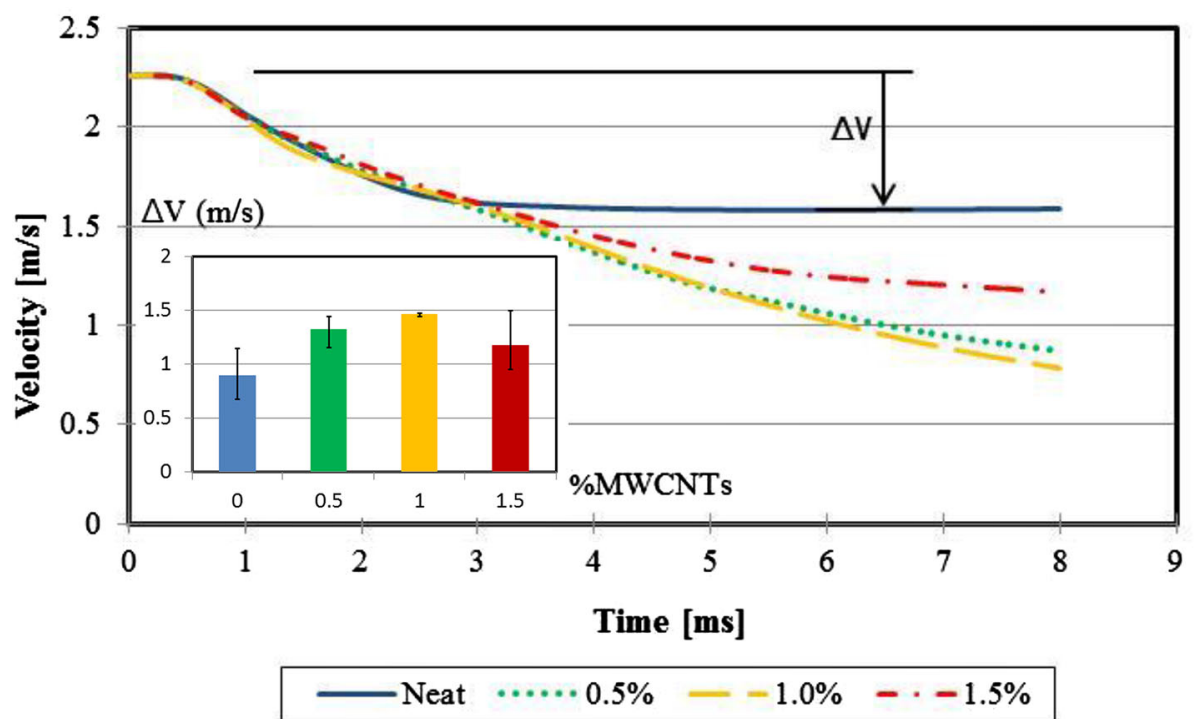

Fig. 5 Effect of MWCNTs on impact striker velocity. Inset shows the slowdown of the impact striker in PC incorporating MWCNTs.

Table 3 Effect of MWCNTs content on maximum absorbed impact energy in J.

\begin{tabular}{c|c|c|c|c}
\hline & Neat & $0.5 \%$ & $1.0 \%$ & $1.5 \%$ \\
\hline \hline SP1 & 22.13 & 36.04 & 36.43 & 28.30 \\
\hline SP2 & 26.42 & 35.38 & 36.09 & 30.80 \\
\hline SP3 & 31.80 & 31.86 & 36.58 & 36.70 \\
\hline Mean \pm SD & $26.8 \pm 4.8$ & $34.4 \pm 2.2$ & $36.4 \pm 0.3$ & $31.9 \pm 4.3$ \\
\hline
\end{tabular}

To examine effect of adding MWCNTs on the fracture behaviour of PCs, the ductility was evaluated by calculating the ductility index $(D I)$ after (Beaumont et al. 1975; Park et al. 2000; Pegoretti et al. 2008) for different mixes as per Eq. (4)

$$
D I(\%)=\frac{E_{p}}{E_{i}} \times 100
$$

where $E_{i}$ is the initiation energy and $E_{p}$ is the propagation energy. In this study, the initiation and propagation energies are considered as the energies absorbed before and after reaching the peak force, respectively. The summation of the initiation $E_{i}$ and propagation $E_{p}$ energies yields the maximum (total) absorbed energy $E_{T}$ reported in Table 3. Different absorbed energies along with ductility indices are listed in Table 4. For the cases of neat, 0.5, 1.0, $1.5 \mathrm{wt} \%$ MWCNTs, the ductility indices (DIs) were 2.79, 4.65, 3.63, and 4.74, respectively. Comparison of the ductility indices of the different PC mixes shows that with the addition of MWCNTs, PC with MWCNTs becomes more ductile (i.e. capable of dissipating energy prior to failure) than neat PC. While the initiation energies do not differ significantly between PCs with different MWCNTs contents, the propagation energies differ significantly. The DI combines the change in both the initiation and propagation energies. The significant increase in propagation energy/ductility of PCs with MWCNTs confirms the role of MWCNTs in dissipating energy during impact loading.

The compressive strength test was performed on cubes made of the four PC mixes. As shown in Table 5, adding $0.5 \mathrm{wt} \%$ MWCNTs increased the compressive strength of PC by $10 \%$, while adding 1.0 and $1.5 \mathrm{wt} \%$ MWCNTs decreased the strength by 1.5 and $3.0 \%$, respectively. Statistical analysis using Student's t-test was performed on test results and proved that the difference between the compressive strength of the PC mixes with and without MWCNTs was statistically significant only for $0.5 \mathrm{wt} \%$ MWCNTs. Although statistically significant, the limited increase in compressive strength of PC due to the addition of $0.5 \mathrm{wt} \%$ MWCNTs suggests that MWCNTs do not have an

Table 4 Ductility index (DI) of PC with varying contents of MWCNTs in \%.

\begin{tabular}{c|c|c|c|c}
\hline & Neat & $0.5 \%$ & $1.0 \%$ & $1.5 \%$ \\
\hline \hline Initiation energy $\left(E_{i}\right)(\mathrm{J})$ & 5.84 & 6.27 & 7.90 & 5.37 \\
\hline Propagation energy $\left(E_{p}\right)(\mathrm{J})$ & 16.29 & 29.11 & 28.67 & 25.43 \\
\hline Ductility Index $(D I)(\%)$ & 2.79 & 4.65 & 3.63 & 4.74 \\
\hline
\end{tabular}


Table 5 Compressive strength of PC with varying contents of MWCNTs in MPa.

\begin{tabular}{c|c|c|c|c}
\hline & Neat & $0.5 \%$ & $1.0 \%$ & $1.5 \%$ \\
\hline \hline SP1 & 30.37 & 31.94 & 28.90 & 27.92 \\
\hline SP2 & 27.40 & 31.36 & 28.60 & 29.31 \\
\hline SP3 & - & 31.97 & 27.88 & 27.10 \\
\hline Mean \pm SD & $28.9 \pm 2.1$ & $31.8 \pm 0.3$ & $28.5 \pm 0.5$ & $28.1 \pm 1.1$ \\
\hline
\end{tabular}

impact on the compressive strength of PC. All PC compression specimens failed due to excessive deformations and no sudden fracture was observed.

Stress-strain curves of the flexural tests of neat PC and PC incorporating MWCNTs were plotted and presented in Fig. 6. The Young's modulus of elasticity represented by the initial slope of the curve was computed for each mix and the variation of this modulus is shown as an inset in Fig. 6. It is shown that the modulus of elasticity of PC was increased by $15 \%$ with adding $0.5 \mathrm{wt} \%$ MWCNTs, and decreased by $40 \%$ with $1.5 \mathrm{wt} \%$ MWCNTs. No significant change was observed with adding $1.0 \mathrm{wt} \%$ MWCNTs. Statistical analysis using Student's t-test proved that there is no significant difference in the case of 0.5 , and $1.0 \mathrm{wt} \% \mathrm{MWCNTs}$, but a significant reduction with PC incorporating $1.5 \mathrm{wt} \%$ MWCNTs. The insignificant statistical difference for the 0.5 and $1.0 \mathrm{wt} \%$ MWCNTs cases could be attributed to the relatively high standard deviation of 1.46 and $1.38 \mathrm{GPa}$ respectively. The effect of adding MWCNTs on the strength and strain capacities of PC is shown in Tables 6 and 7, respectively. Incorporating 0.5 and $1.0 \mathrm{wt} \%$ MWCNTs in the PC mix increased the flexural strength by 41 , and $26 \%$, respectively, while the $1.5 \mathrm{wt} \%$ MWCNTs decreased the flexural strength by $2 \%$. Significant statistical difference between flexural strengths in the case of 0.5 and $1.0 \mathrm{wt} \%$ MWCNTs was proven by statistical analysis, while no statistical difference was found for $1.5 \mathrm{wt} \%$ MWCNTs. Moreover, failure strain was increased by 3, 12, and $65 \%$ with addition of $0.5,1.0,1.5 \mathrm{wt} \%$ MWCNTs, respectively. For failure strains, no statistically significant difference was found in the case of $0.5 \mathrm{wt} \%$ MWCNTs, while a significant difference was proven with 1.0 and $1.5 \mathrm{wt} \%$ MWCNTs. The significant increase in the failure strain associated with increasing the amount of MWCNTs could be attributed to the reduction on flowability, which develops more entrapped air as discussed later.

Moreover, the flexural toughness, defined as the static absorbed energy per unit volume, for different mixes is reported in Table 8 . The table presents significant increases in static absorbed energy with the addition of MWCNTs. For instance, 41, 36, and $54 \%$ increase in flexural absorbed energy is reported for $0.5,1.0$, and $1.5 \mathrm{wt} \%$ MWCNTs, respectively. Similar to the DI, the flexural toughness combines the change on both flexure strength and strain capacity due to the addition of MWCNTs. It is also important to mention that there is no explicit relationship between the static absorbed energy (Table 8) and impact absorbed energy (Table 3). This is because the impact energy depends significantly on many parameters such as strain rate, shape of projectile, material and stiffness of the projectile and the specimen, incident energy, and support boundary conditions. However, static absorbed energy might be correlated to

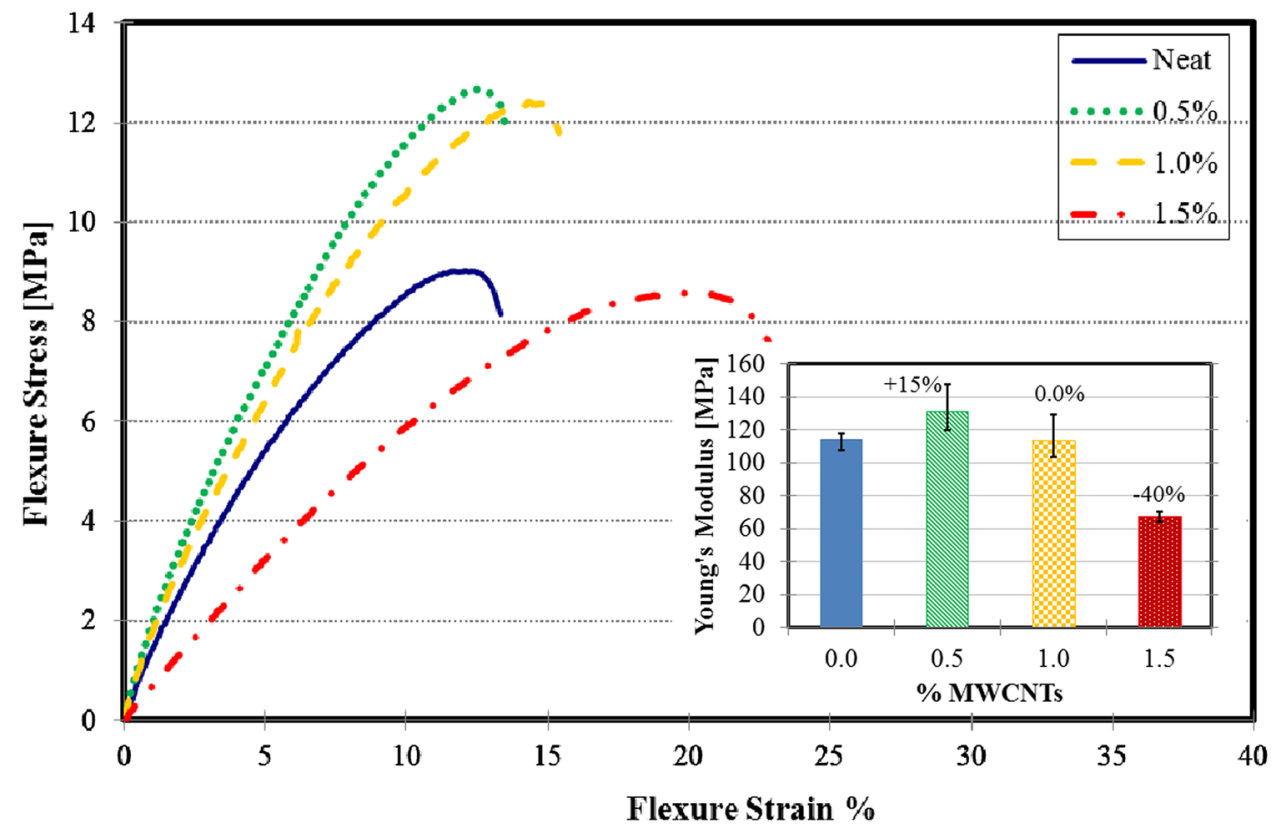

Fig. 6 Stress-strain curves of flexure test of PC with varying MWCNTs content. Inset shows the change in modulus of elasticity of PC with varying MWCNTs content. 
Table 6 Flexural strength of PC with varying MWCNTs content in MPa.

\begin{tabular}{c|c|c|c|c}
\hline & Neat & $0.5 \%$ & $1.0 \%$ & $1.5 \%$ \\
\hline \hline SP1 & 9.03 & 12.69 & 12.41 & 8.60 \\
\hline SP2 & 9.82 & 12.60 & 10.91 & 8.90 \\
\hline SP3 & 8.77 & 13.71 & 11.36 & 9.60 \\
\hline Mean \pm SD & $9.2 \pm 0.5$ & $13.0 \pm 0.6$ & $11.6 \pm 0.8$ & $9.0 \pm 0.5$ \\
\hline
\end{tabular}

Table 7 Flexural failure strain of PC with varying MWCNTs content in (\%).

\begin{tabular}{c|c|c|c|c}
\hline & Neat & $0.5 \%$ & $1.0 \%$ & $1.5 \%$ \\
\hline \hline SP1 & 13.32 & 12.69 & 15.40 & 23.70 \\
\hline SP2 & 13.69 & 12.60 & 13.36 & 20.27 \\
\hline SP3 & 12.26 & 13.71 & 15.19 & 20.96 \\
\hline Mean \pm SD & $13.1 \pm 0.7$ & $13.0 \pm 0.6$ & $14.7 \pm 1.1$ & $21.6 \pm 1.8$ \\
\hline
\end{tabular}

Table 8 Flexural toughness of PC with varying MWCNTs content in $\mathrm{N} \mathrm{mm} / \mathrm{mm}^{3}$.

\begin{tabular}{c|c|c|c|c}
\hline & Neat & $0.5 \%$ & $1.0 \%$ & $1.5 \%$ \\
\hline SP1 & 0.8 & 1.11 & 1.24 & 1.38 \\
\hline SP2 & 0.9 & 1.03 & 0.95 & 1.11 \\
\hline SP3 & 0.72 & 1.28 & 1.10 & 1.24 \\
\hline Mean \pm SD & $0.81 \pm 0.09$ & $1.14 \pm 0.13$ & $1.10 \pm 0.15$ & $1.24 \pm 0.14$ \\
\hline
\end{tabular}

impact energy and thus it can provide a useful indication of the performance of PCs with various MWCNTs contents to impact loading. Finally, the shear strength of PC incorporating MWCNTs is presented in Table 9. The shear strength of PC was decreased by 5,13 , and $9 \%$ for addition of 0.5 , 1.0, and $1.5 \mathrm{wt} \%$ MWCNTs, respectively. The static shear test showed MWCNTs incapable of improving the shear strength of PC; statistical analysis using Student's t-test with a $90 \%$ level of confidence confirmed that the change in the shear strength of PC incorporating varying MWCNTs content to be statistically insignificant. The $90 \%$ confidence level is selected for analyzing the shear test results because of the brittle nature of the shear failure which typically results in relatively high variation on the test results as opposed to other mechanical testing (e.g. flexure or compression) where ductile failure associated with excessive deformation is observed.

Observing the behavior of PC with MWCNTs under compression and flexure stresses, it is obvious that addition of MWCNTs altered its mechanical performance. The results showed that MWCNTs did not have a significant effect on the compressive strength of PC. However, MWCNTs significantly improved the flexural strength, stiffness and failure strain of PC. The significance of MWCNTs on flexural strength might be attributed to the ability of the MWCNTs to produce a new epoxy-MWCNTs nanocomposite with improved mechanical properties; specially the flexural strength and the failure strain. These observations are supported by other researchers (Ganguli et al. 2005) who showed functionalized MWCNTs to act as microfibers, each individual fiber being 10-nm diameter and 10-30 $\mu \mathrm{m}$ long. These microfibers were able to bridge micro and submicron cracks in the polymer matrix and improve mechanical properties. Moreover, the functionalization of MWCNTs allows the MWCNTs to chemically bond to the epoxy matrix and thus alter the strength, failure strains and stiffness of the PC incorporating MWCNTs as reported elsewhere (Zhu et al. 2003; Zhu et al. 2004).

It can also be observed that by increasing the MWCNTs content, there is an increase followed by a decrease in the

Table 9 Shear strength of PC with varying MWCNTs content in MPa.

\begin{tabular}{c|c|c|c|c}
\hline & Neat & $0.5 \%$ & $1.0 \%$ & $1.5 \%$ \\
\hline \hline SP1 & 4.70 & 4.71 & 4.22 & 4.48 \\
\hline SP2 & 5.14 & 4.71 & 4.29 & 4.64 \\
\hline SP3 & 5.01 & 4.68 & 4.42 & 4.44 \\
\hline Mean \pm SD & $5.0 \pm 0.2$ & $4.7 \pm 0.0$ & $4.3 \pm 0.1$ & $4.5 \pm 0.1$ \\
\hline
\end{tabular}


mechanical properties. This trend can be clearly observed in Tables 3 and 6, and the inset of Fig. 6 for the impact energy, flexure strength, and Young's modulus, respectively. This trend is a result of two counteracting factors. First, with relatively small amounts of MWCNTs (e.g. $0.5 \mathrm{wt} \%$ and below), there is insufficient amount of CNTs that can introduce significant effect on the mechanical properties of polymer concretes. As the amount of CNTs increases, the improvements increase. On the other hand, the inefficiency of $1.5 \mathrm{wt} \%$ MWCNTs content can be attributed to the reduction of PC flowability at high content of MWCNTs. While the effect of MWCNTs on PC flowability was limited in the case of 0.5 and $1.0 \mathrm{wt} \%$ the addition of $1.5 \mathrm{wt} \%$ MWCNTs reduced the flowability significantly. This reduction in PC flowability might result in entrapping air that reduces the mechanical properties of $\mathrm{PC}$ with $1.5 \mathrm{wt} \%$ MWCNTs.

To prove the effect of air on the behavior of PC, air content was measured for the four PCs with different MWCNTs contents using the gravimetric method. The air contents for the PCs with neat, 0.5, 1.0, and $1.5 \mathrm{wt} \%$ MWCNTs were $12.9,7.6,7.3$, and $10.2 \%$ respectively as shown in Fig. 7. Two main observations can be deduced from the air content measurements. First, there is a general reduction in air content due to the addition of MWCNTs, which may also contribute to the improvement in various mechanical properties. This can be attributed to the improved cohesion of the matrix and MWCNTs given the possible reaction between MWCNTs and epoxy matrix. Second, there is considerable increase in the air content when the MWCNTs content reached $1.5 \mathrm{wt} \%$ compared with the 0.5 and $1.0 \mathrm{wt} \%$ MWCNTs. As explained earlier, this increase in air content is attributed to the decrease in flowability of the epoxy resin with $1.5 \mathrm{wt} \%$ MWCNTs and causes a relative decrease in the mechanical properties of PC. Furthermore, the air content analysis shows that the addition of $0.5-1.0 \mathrm{wt} \%$ MWCNTs yields the lowest air contents of PC among all the examined MWCNTs contents. As a result, the mechanical testing showed that the cases of 0.5 and $1.0 \mathrm{wt} \%$ MWCNTs outperformed the neat and $1.5 \mathrm{wt} \%$ MWCNTs cases. Further investigations are warranted to determine the optimal content of MWCNTs for

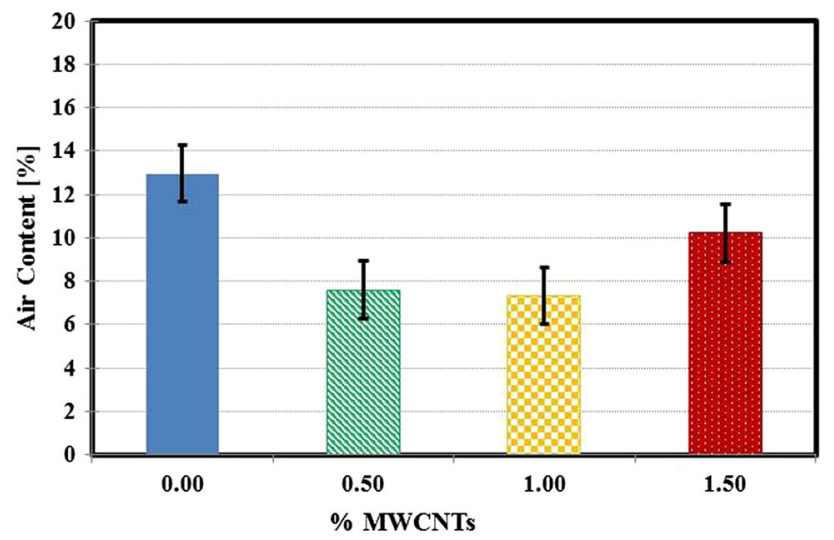

Fig. 7 Significance of MWCNTs content on air content in PC mixtures. each mechanical property, which may possibly fall between 0.5 and $1.0 \mathrm{wt} \%$ MWCNTs.

\subsection{Cracking Pattern of PC Under Impact}

To further understand the significance of MWCNTs we examined the cracking pattern of PC with and without MWCNTs under impact load. Crack pattern analysis was performed to assess the fracture behaviour of different PCs in lieu of cone damage/cracking analysis typically performed in composite materials subjected to impact loading. Figure 8 shows that in all impact specimens of PC incorporating MWCNTs, four or more concrete crack lines were formed compared with three crack lines formed in neat PC. Therefore, there is an obvious increase in the number of crack lines with the addition of MWCNTs. It is widely accepted that the increase in cracking density provides an indication of ductility and better material ability to dissipate energy as in the case of PC incorporating MWCNTs. In this case, the addition of MWCNTs acts like rebar in concrete, which results in distributing the strains and developing smaller and more closely spaced cracks. In order to understand the formation of radial cracks, analysis of the cracking pattern is established in accordance with yield line theory. In this analysis, the radial cracks were assumed to act as yield lines. In a typical orthotropic reinforced concrete plate with a circular boundary condition and subjected to a static central point load, a large number of radial cracks is expected to form (Fig. 9a) (Johansen 1962). However, in heterogeneous materials without reinforcement such as PC subjected to impact load, the cracking pattern would differ resulting on fewer crack lines as observed. Here, one needs to realize that the high strain rate of the impact load $\left(10^{-3}-10^{-2} \mathrm{~s}^{-1}\right)$ is three to four orders of magnitude faster than static loading $\left(10^{-6}-10^{-5} \mathrm{~s}^{-1}\right)$ (Riisgaard et al. 2007) which leads to forming instantaneous support points rather than the continuous circular support that would respond to static loading. The internal energy (I.E.) along the crack lines can still be computed following yield line theory as:

$$
\text { I.E. = n.M.a. } \theta
$$

where $n$ is number of fragments or number of crack lines, $M$ is the moment carrying capacity per unit length, $a$ is the

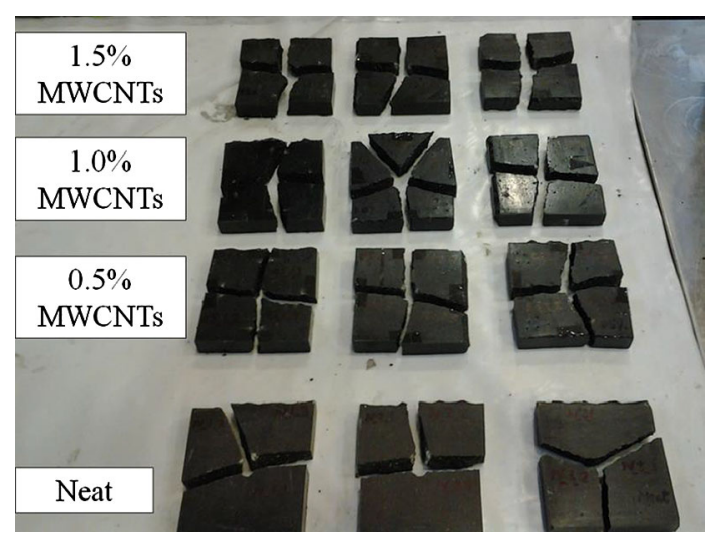

Fig. 8 Cracking pattern due to impact of PC with varying MWCNTs content. 
(a)

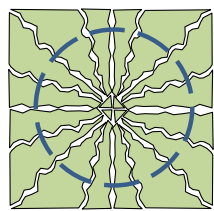

(c)
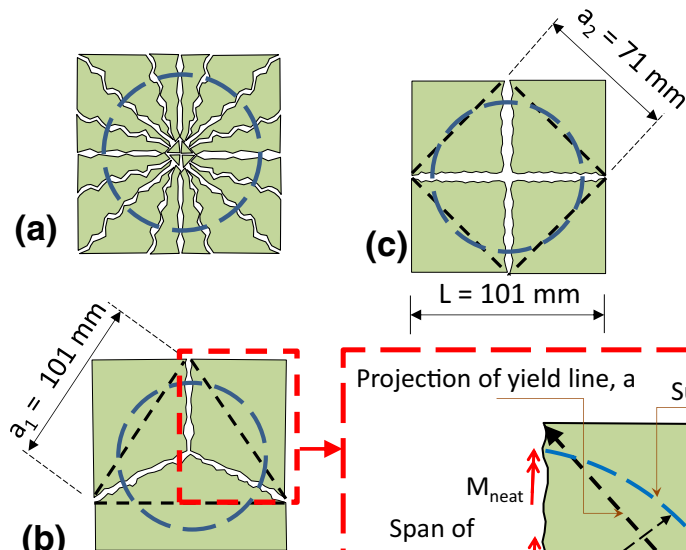

(b) $\mathrm{L}=101 \mathrm{~mm}$
Projection of yield line, a support line

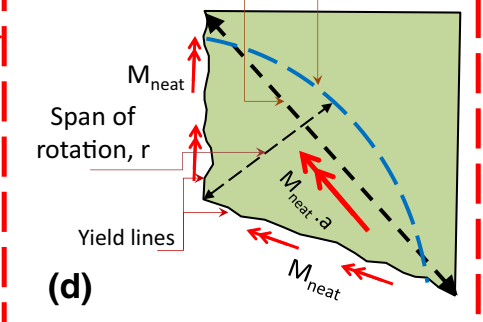

(d)

Fig. 9 Yield line analysis for cracking pattern a crack lines for homogenous circular plate subjected to static loading, b crack lines for neat PC, c crack lines for PC incorporating $1.0 \%$ MWCNTs, and d analysis for internal energy consumed in one fragment.

projection of the yield line on the axis of rotation, and $\theta=\frac{\Delta}{r}$ is the angle of rotation of fragments in degree, $\Delta$ is the center point displacement, and $r$ is the rotation span which equals to the radius of the circular plate as indicated in Fig. 9d. By considering neat $\mathrm{PC}$ and $\mathrm{PC}$ incorporating $1.0 \mathrm{wt} \%$
MWCNTs for comparison, the carrying moment capacities per unit length for the neat $\left(M_{\text {neat }}\right)$ and $1.0 \mathrm{wt} \%$ MWCNTs $\left(M_{1.0} \%\right)$ are computed from the flexure tests as 14.2 and $20.5 \mathrm{~N} \mathrm{~m} / \mathrm{mm}$, respectively. The maximum deflections observed during the impact tests were 12.5- and 10.8-mm for the neat and $1.0 \mathrm{wt} \%$ MWCNTs, respectively. Considering the geometrical relationships for the two cases as shown in Fig. 9b, c, the ratio of the absorbed energy between the neat PC and PC incorporating $1.0 \mathrm{wt} \%$ MWCNTs can be written as a function of the ratio of number of crack lines as follows

$$
\frac{I . E .(1.0 \%)}{I . E .(\text { Neat })}=\frac{n_{1.0 \%} \cdot M_{1.0 \%} \cdot a_{2} \cdot \Delta_{1.0} \%}{n_{\text {neat }} \cdot M_{\text {neat }} \cdot a_{1} \cdot \Delta_{\text {neat }}} \approx 0.88 \frac{n_{1.0 \%}}{n_{\text {neat }}}
$$

$a_{1}$ and $a_{2}$ are the projected lengths of the cracks as shown in Figs. $9 \mathrm{~b}$ and 9c, respectively. Since the ratio of absorbed energy between neat PC and PC incorporating $1.0 \mathrm{wt} \%$ MWCNTs is 1.36 as observed in the impact test (Table 3), the ratio of number of crack lines $n_{1.0 \%} / n_{\text {neat }}$ would be 1.55 . This simple analysis proves that given the geometry of the impact test, the moment capacity and displacement observations of PC with and without MWCNTs, energy equilibrium necessitates increasing the number of crack lines from three to four or five in order to achieve the reported increase in the absorbed energy. This is evident from experimental observation of the cracking pattern of PC with MWCNTs.

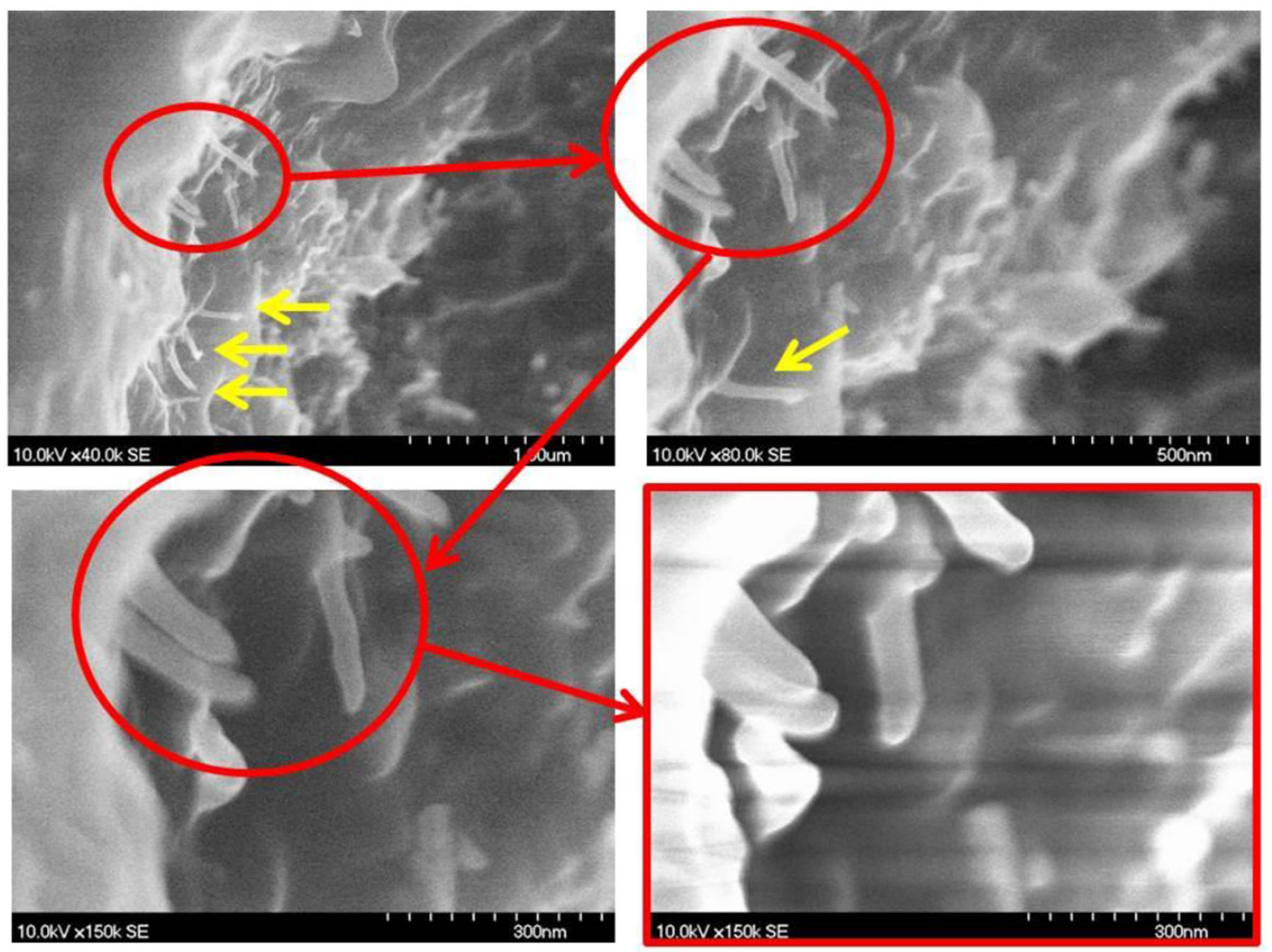

Fig. 10 SEM images of epoxy incorporating $1.0 \%$ MWCNTs with different magnifications showing how CNTs are connected to the polymer matrix. 


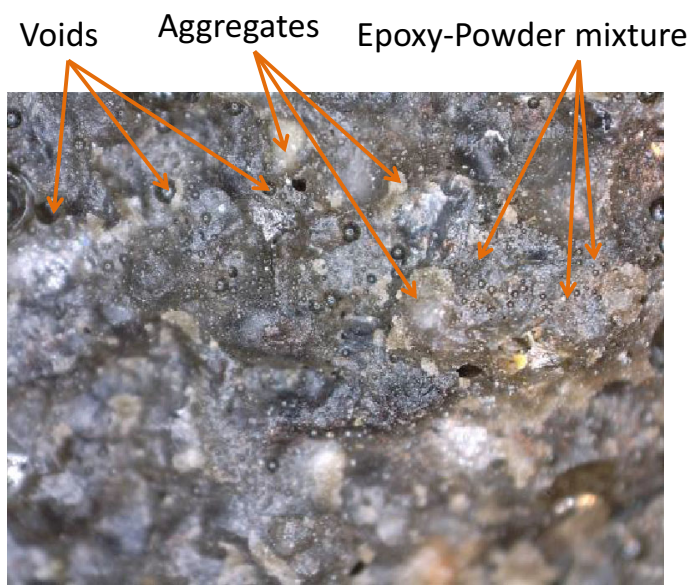

(a) Neat epoxy PC

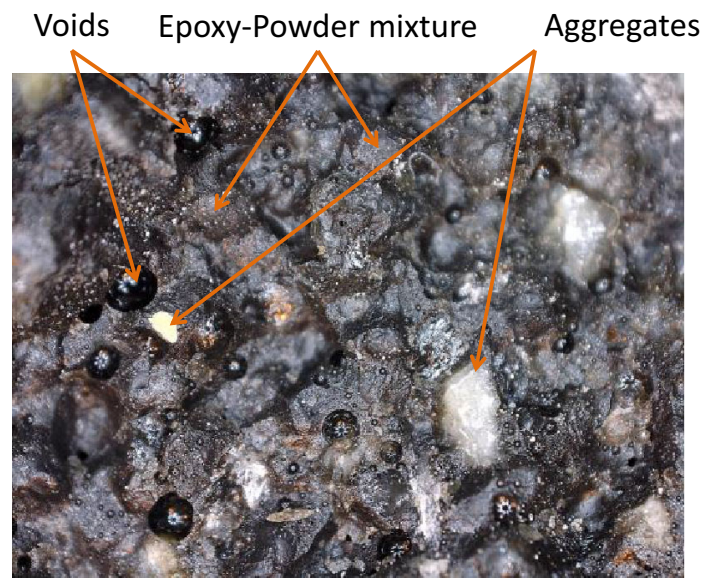

(b) $1.0 \%$ MWCNTs-epoxy PC

Fig. $11 \times 100$ magnification microscopic images showing homogenous mixture of polymer concrete composites.

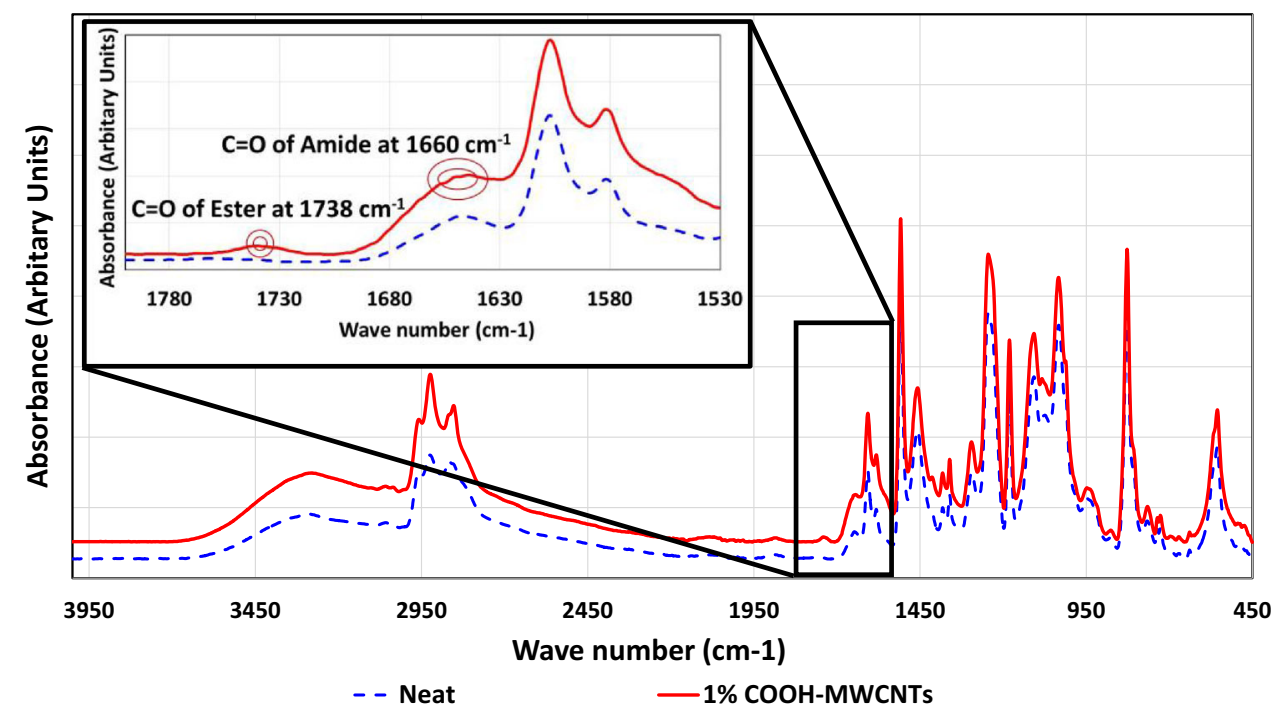

Fig. 12 FTIR spectra of neat epoxy and epoxy incorporating COOH-functionalized MWCNTs. Inset shows close look of the FTIR spectra at wave numbers of interest.

\subsection{Microstructural Features of PC}

Fracture surfaces of epoxy sample incorporating $1.0 \mathrm{wt} \%$ MWCNTs were investigated by SEM. SEM images in Fig. 10 show well dispersed MWCNTs in the epoxy matrix. Figure 10 displays four images of the same fracture surface with varying magnifications showing MWCNTs (indicated by yellow arrows) as longitudinal tubular fibers bridging epoxy fracture surfaces and connecting epoxy parts together. SEM images provide excellent evidence on the role that MWCNTs play in keeping the epoxy matrix intact and limiting crack propagation. This explains the ability of MWCNTs to increase energy absorption and energy dissipation inside PC. Furthermore, the microscopic images shown in Fig. 11 prove that a homogenous mixture of polymer concrete composites is achieved with and without the addition of MWCNTs.

This improvement in mechanical properties of epoxy might be attributed to the chemical reaction between the carboxylic groups on the MWCNTs surface and the epoxy groups. This reaction was confirmed from the FTIR analysis of neat epoxy and epoxy/COOH-MWCNTs ( $1 \mathrm{wt} \%$ ) shown in Fig. 12. In FTIR, the presence of any chemical bond can be identified by the location and the intensity of its peak along the wave length spectra as reported in the literature. The typical characteristic peaks of the siloxane-epoxy appeared at $3250-3500 \mathrm{~cm}^{-1}\left(v_{\mathrm{O}-\mathrm{H}}\right), 2750-2940 \mathrm{~cm}^{-1}$ $\left(v_{\mathrm{sym}}\right.$ and $v_{\mathrm{asym}}$ of $\left.\mathrm{C}-\mathrm{H}\right), 1612 / 1510 \mathrm{~cm}^{-1}$ (aromatic $\mathrm{C}=\mathrm{C}$ ), $1460 \mathrm{~cm}^{-1}\left(\delta_{\mathrm{C}-\mathrm{H}}, \quad \mathrm{CH}_{2}\right.$ and $\left.\mathrm{CH}_{3}\right), \quad 1039-1100 \mathrm{~cm}^{-1}(-$ $v_{\mathrm{Si}-\mathrm{O}-\mathrm{Si}}$ and $\left.v_{\mathrm{C}-\mathrm{O}-\mathrm{C}}\right), 1250-828 \mathrm{~cm}^{-1}\left(\delta_{\mathrm{C}-\mathrm{H}}\right.$ in $\left.\mathrm{Si}-\mathrm{CH}_{3}\right)$, and $560 \mathrm{~cm}^{-1}\left(\delta_{\mathrm{Si}-\mathrm{O}-\mathrm{Si}}\right)$ as reported by Byczyński et al. $(2015)$, Wang et al. (2011), and Kwon et al. (2011). Similar peak absorptions appeared for epoxy/COOH-MWCNTs shown in the same figure. However, comparison of the carbonyl region in both spectra, as shown in Fig. 12 inset, confirms the presence of small absorption peak at $1738 \mathrm{~cm}^{-1}$ in the epoxy/COOH-MWCNTs specimen that does not appear in the neat epoxy reaction. This peak is attributed to $\mathrm{C}=\mathrm{O}$ of ester formed during the first mixing step of MWCNTs and 
epoxy resin by the reaction of carboxylic group of MWCNTs and the hydroxyl group of epoxy (Zou et al. 2008; Kim et al. 2004). Furthermore, during the second step of curing epoxy, the remaining carboxyl groups reacted with the hardener and formed amide groups resulting in $\mathrm{C}=\mathrm{O}$ peak at $\sim 1660 \mathrm{~cm}^{-1}$ as shown in the inset of Fig. 12. Similar $\mathrm{C}=\mathrm{O}$ peaks were reported before in using $\mathrm{COOH}$ functionalized MWCNTs for improving fracture toughness of carbon fiber composites (Borowski et al. 2015). It is important to note that that amide peak in the COOH-MWCNTs-epoxy nanocomposite at $1660 \mathrm{~cm}^{-1}$ appears combined with the aromatic and $\mathrm{N}-\mathrm{H}$ deformation peaks in neat epoxy (Tsai et al. 2015). This explains the peak appearing in the neat epoxy spectra and the difference in the relative heights of this peak in both spectra.

The above microstructural analysis shows that the improvement of mechanical properties of PC with MWCNTs can be attributed to the chemical reactivity of the $\mathrm{COOH}$ functionalized MWCNTs with the polymer matrix producing a new epoxy-MWCNTs nanocomposite with improved mechanical characteristics specifically strength, ductility and energy absorption. In the meantime, it is obvious that the relatively high aspect ratio of MWCNTs results in enabling them to work as fibers reinforcing PC and limiting crack propagation and enabling energy dissipation. Further research is warranted to understand the fracture mechanics of PC incorporating MWCNTs. It is important to understand how the change in the epoxy matrix due to incorporating MWCNTs would affect the adhesion between epoxy and the aggregate particles compared with neat PC. Future research should enable engineering new impact resistant PCs needed from many applications.

\section{Conclusions}

PC incorporating MWCNTs has a higher impact resistance than neat PC. In particular, incorporating $1.0 \mathrm{wt} \%$ MWCNTs in PC per weight of the epoxy resin during PC fabrication resulted in significantly increased impact energy absorption of PC by $36 \%$ compared with neat PC. Moreover, PC incorporating MWCNTs was more capable of dissipating the impact energy compared with neat PC. The increase in energy dissipation for PC incorporating MWCNTs resulted in a significant reduction in impact striker velocity after penetration and an increase of cracking density compared with neat PC. This improvement in the impact energy absorption and dissipation are in line with the improvement in the flexural strength of PC and might be explained by the change in the microstructure of the epoxy matrix. The change in the microstructure stems from the ability of the $\mathrm{COOH}$ functionalized MWCNTs to bridge the polymer matrix microcracks with its $(10-30 \mu \mathrm{m})$ length and very high aspect ratio (about 1000) to continue carrying load. Microstructural investigations proved the good dispersion of MWCNTs in PC matrix and provided evidence that a chemical reaction of $\mathrm{COOH}$ functionalized MWCNTs with epoxy matrix takes place creating a new epoxy-MWCNTs nanocomposite with improved mechanical properties specifically ductility and energy absorption. On the other hand, the addition of $1.5 \mathrm{wt} \%$ MWCNTs limited the improvements on the impact and flexure of PC. Such relatively large amounts of MWCNTs reduce the flowability of the epoxy resin resulting in more entrapped air within the PC material. The presence of entrapped air adversely affects the mechanical properties of PC. In general, the changes in the microstructure of PC using $1.0 \mathrm{wt} \%$ MWCNTs can benefit the design of new class of PC structural elements with enhanced impact resistance and ductility for infrastructure applications.

\section{Acknowledgments}

This work has been supported by STC.UNM fund for investigating fatigue and impact strength of PC using MWCNTs. Support to the third author by STDF-CSE 5213 Polymer Nanocomposite Centre, Egyptian Petroleum Research Institute (EPRI) is much appreciated. The donation of polymer concrete materials by Transpo Industries is greatly appreciated.

\section{Open Access}

This article is distributed under the terms of the Creative Commons Attribution 4.0 International License (http:// creativecommons.org/licenses/by/4.0/), which permits unrestricted use, distribution, and reproduction in any medium, provided you give appropriate credit to the original author(s) and the source, provide a link to the Creative Commons license, and indicate if changes were made.

\section{References}

ACI Committee 548. (2009). Polymers and adhesives in concrete. State of the Art Report.

Algaard, W., Lyle, J., \& Izatt, C. (2005). Perforation of composite floors. In 5th European LS-DYNA users conference, Birmingham, UK (pp. 1123-1130).

ASTM C1437. (2009). Standard test method for flow of hydraulic cement mortar. West Conshohocken, PA: ASTM International.

ASTM C579-01. (2012). Standard test methods for compressive strength of chemical-resistant mortars, grouts, monolithic surfacings, and polymer concretes. West Conshohocken, PA: ASTM International.

ASTM C78. (2002). Standard test method for flexural strength of concrete (using simple beam with third point loading). West Conshohocken, PA: ASTM International.

ASTM D4475. (2008). Standard test method for apparent horizontal shear strength of pultruded reinforced plastic rods by the short-beam method. West Conshohocken, PA: ASTM International.

ASTM D7136/D7136M. (2007). Standard test method for measuring the damage resistance of a fiber-reinforced 
polymer matrix composite to a drop-weight impact event. West Conshohocken, PA: ASTM International.

Batarlar B. (2013). Behavior of reinforced concrete slabs subjected to impact loads. MSc Thesis, Izmir Institute of Technology, Izmir, Turkey.

Beaumont, P. W. R., Riewald, P. G., \& Zweben, C. (1975). Methods for improving the impact resistance of composite materials. In Foreign object impact damage to composites. West Conshohocken, PA: ASTM International.

Bignozzi, M. C., Saccani, A., \& Sandrolini, F. (2000). New polymer mortars containing polymeric wastes. Part 1 . Microstructure and mechanical properties. Composites Part A: Applied Science and Manufacturing, 31(2), 97-106.

Borowski, E., Soliman, E., Kandil, U. F., \& Taha, M. R. (2015). Interlaminar fracture toughness of CFRP laminates incorporating multi-walled carbon nanotubes. Polymers, 7(6), $1020-1045$.

Byczyński, Ł., Dutkiewicz, M., \& Maciejewski, H. (2015). Synthesis and properties of high-solids hybrid materials obtained from epoxy functional urethanes and siloxanes. Progress in Organic Coatings, 84, 59-69.

Choudhary, V., \& Gupta, A. (2011). Polymer/carbon nanotube nanocomposites. Carbon Nanotubes-Polymer Nanocomposites, 2011, 65-90.

Ganguli, S., Bhuyan, M., Allie, L., \& Aglan, H. (2005). Effect of multi-walled carbon nanotube reinforcement on the fracture behavior of a tetrafunctional epoxy. Journal of Materials Science, 40(13), 3593-3595.

Gojny, F. H., Wichmann, M. H., Fiedler, B., Bauhofer, W., \& Schulte, K. (2005). Influence of nano-modification on the mechanical and electrical properties of conventional fibrereinforced composites. Composites Part A: Applied Science and Manufacturing, 36(11), 1525-1535.

Huang, J., Zhang, Q., Zhao, M., \& Wei, F. (2012). A review of the large-scale production of carbon nanotubes: The practice of nanoscale process engineering. Chinese Science Bulletin, 57(2-3), 157-166.

ISO 6603-2. (2000). Plastics-Determination of puncture impact behaviour of rigid plastics-Part 2: Instrumented impact testing. Dublin, Ireland: European Standards, National Standards Authority of Ireland.

Izatt, C., May, I. M., Lyle, J., Chen, Y., \& Algaard, W. (2009). Perforation owing to impacts on reinforced concrete slabs. Proceedings of the Institution of Civil Engineers-Structures and Buildings, 162(1), 37-44.

Jiang, X., \& Drzal, L. T. (2011). Improving electrical conductivity and mechanical properties of high density polyethylene through incorporation of paraffin wax coated exfoliated graphene nanoplatelets and multi-wall carbon nano-tubes. Composites Part A: Applied Science and Manufacturing, 42(11), 1840-1849.

Jo, B. W., Tae, G. H., \& Kim, C. H. (2007). Uniaxial creep behavior and prediction of recycled-PET polymer concrete. Construction and Building Materials, 21(7), 1552-1559.

Johansen, K. W. (1962). Yield-line theory. London, UK: Cement and Concrete Association, Technology \& Engineering.

Kim, W. J., Kang, S. O., Ah, C. S., Lee, Y. W., Ha, D. H., Choi, I. S., et al. (2004). Functionalization of shortened SWCNTs using esterification. Bulletin-Korean Chemical Society, 25(9), 1301-1302.

Kwon, Y., Yim, B. S., Kim, J. M., \& Kim, J. (2011). Mechanical and wetting properties of epoxy resins: Amine-containing epoxy-terminated siloxane oligomer with or without reductant. Microelectronics Reliability, 51(4), 819-825.

Laurenzi, S., Pastore, R., Giannini, G., \& Marchetti, M. (2013). Experimental study of impact resistance in multi-walled carbon nanotube reinforced epoxy. Composite Structures, 99, 62-68.

Li, W., \& Xu, J. (2009). Mechanical properties of basalt fiber reinforced geopolymeric concrete under impact loading. Materials Science and Engineering A, 505(1), 178-186.

Ma, P. C., \& Kim, J. K. (2011). Carbon nanotubes for polymer reinforcement. Boca Raton, FL: CRC Press.

Magrez, A., Seo, J. W., Smajda, R., Mionić, M., \& Forró, L. (2010). Catalytic CVD synthesis of carbon nanotubes: Towards high yield and low temperature growth. Materials, 3(11), 4871-4891.

Martínez-Barrera, G., \& Brostow, W. (2010). Effect of marble particle size and gamma irradiation on mechanical properties of polymer concrete. e-Polymers, 10(1), 663-676.

Nam, I. W., \& Lee, H. K. (2015). Image analysis and DC conductivity measurement for the evaluation of carbon nanotube distribution in cement matrix. International Journal of Concrete Structures and Materials, 9(4), $427-438$.

Orak, S. (2000). Investigation of vibration damping onp concrete with polyester resin. Cement and Concrete Research, 30(2), 171-174.

Park, S. J., Park, W. B., \& Lee, J. R. (2000). Characterization of the impact properties of three-dimensional glass fabric-reinforced vinyl ester matrix composites. Journal of Materials Science, 35(24), 6151-6154.

Pegoretti, A., Cristelli, I., \& Migliaresi, C. (2008). Experimental optimization of the impact energy absorption of epoxycarbon laminates through controlled delamination. Composites Science and Technology, 68(13), 2653-2662.

Radlińska, A., McCarthy, L. M., Matzke, J., \& Nagel, F. (2014). Synthesis of DOT use of beam end protection for extending the life of bridges. International Journal of Concrete Structures and Materials, 8(3), 185-199.

Rebeiz, K. S., \& Craft, A. P. (2002). Polymer concrete using coal fly ash. Journal of Energy Engineering-ASCE, $128(3), 62-73$.

Rebeiz, K. S., Serhal, S. P., \& Craft, A. P. (2004). Properties of polymer concrete using fly ash. Journal of Materials in Civil Engineering, 16(1), 15-19.

Reda Taha, M. M., Kandil, U., \& Soliman, E. (2013). Generation of polymer concrete incorporating carbon nanotubes. US Patent \# 8,426,501 B1.

Reda Taha, M. M., Taha, E. O., \& Genedy, M. (2014). Monitoring fatigue damage propagation in GFRP using carbon nanotubes, In Proceedings of American Society for Composites 29th technical conference, 16th US-Japan conference on composite materials, San Diego, CA.

Riisgaard, B., Ngo, T., Mendis, P., Georgakis, C. T., \& Stang, H. (2007). Dynamic increase factors for high performance 
concrete in compression using split Hopkinson pressure bar. In International conference of fracture mechanics of concrete structures. Denmark: Technical University of Denmark.

Roessler, D. M. (1965). Kramers-Kronig analysis of reflection data. British Journal of Applied Physics, 16(8), 1119.

Sett, K., \& Vipulanandan, C. (2004). Properties of polyester polymer concrete with glass and carbon fibers. ACI Materials Journal, 101(1), 30-41.

Sharma, R., \& Iqbal, Z. (2004). In situ observations of carbon nanotube formation using environmental transmission electron microscopy. Applied Physics Letters, 84(6), 990-992.

Soliman, E., Al-Haik, M., \& Taha, M. R. (2012a). On and offaxis tension behavior of fiber reinforced polymer composites incorporating multi-walled carbon nanotubes. Journal of Composite Materials, 46(14), 1661-1675.

Soliman, E. M., Sheyka, M. P., \& Taha, M. R. (2012b). Lowvelocity impact of thin woven carbon fabric composites incorporating multi-walled carbon nanotubes. International Journal of Impact Engineering, 47, 39-47.

Swain, S., Sharma, R. A., Patil, S., Bhattacharya, S., Gadiyaram, S. P., \& Chaudhari, L. (2012). Effect of allyl modified/silane modified multiwalled carbon nanotubes on the electrical properties of unsaturated polyester resin composites. Transactions on Electrical and Electronic Materials, 13(6), 267-272.

Tan, C. W., Tan, K. H., Ong, Y. T., Mohamed, A. R., Zein, S. H. S., \& Tan, S. H. (2012). Energy and environmental applications of carbon nanotubes. Environmental Chemistry Letters, 10(3), 265-273.

Tawfik, M. E., \& Eskander, S. B. (2006). Polymer concrete from marble wastes and recycled poly (ethylene terephthalate). Journal of Elastomers and Plastics, 38(1), 65-79.

Ting, J. H., Lyu, J. Y., Huang, F. Y., Li, T. L., Hsu, C. L., \& Liu, C. W. (2008). Synthesis of single-wall carbon nanotubes by atmospheric thermal CVD. In University/Government/Industry Micro/Nano Symposium (UGIM 2008), 17th Biennial (pp. 157-160). Louisville, KY: IEEE.

Tsai, C. W., Wu, K. H., Yang, C. C., \& Wang, G. P. (2015). Adamantane-based epoxy resin and siloxane-modified adamantane-based epoxy resin: Characterization of thermal, dielectric and optical properties. Reactive \& Functional Polymers, 91, 11-18.

Viets, C., Mannov, E., Buschhorn, S., \& Schulte, K. (2009). Laminate lay-up influence on sensing properties of carbon nanotube modified GFRP via electrical conductivity methods. In 16th international conference on composite structures (ICCS 16), Porto, Portugal.

Wang, B., Chen, R., Zhang, T., \& Jiang, X. (2003). The application of polymer concrete in the airfield rapid repair. In Proceedings of the international conference on advances in concrete and structures (ICACS 2003), RILEM Publications, Bagneux, France (pp. 691-695).

Wang, S., Li, Y., Fei, X., Sun, M., Zhang, X., Li, Y., et al. (2011). Preparation of a durable superhydrophobic membrane by electrospinning poly (vinylidene fluoride)(PVDF) mixed with epoxy-siloxane modified $\mathrm{SiO}_{2}$ nanoparticles: A possible route to superhydrophobic surfaces with low water sliding angle and high water contact angle. Journal of Colloid and Interface Science, 359(2), 380-388.

Wang, T., Zhang, J., Bai, W., \& Hao, S. (2013). Forming process and mechanical properties of fibers-reinforced polymer concrete. Journal of Reinforced Plastics and Composites, 32(12), 907-911.

Xu, J. Y., Li, W. M., Fan, F. L., \& Bai, E. L. (2010). Experimental study on impact properties of carbon fiber reinforced geopolymeric concrete using a SHPB. Journal of Building Materials, 13(4), 66-69.

Zamal, H. H. (2011). Monitoring fatigue damage behavior of glass/epoxy composites using carbon nanotubes as sensors. $\mathrm{PhD}$ dissertation, Concordia University, Montreal, Quebec, Canada.

Zhou, D., \& Chow, L. (2003). Complex structure of carbon nanotubes and their implications for formation mechanism. Journal of Applied Physics, 93(12), 9972-9976.

Zhu, J., Kim, J., Peng, H., Margrave, J. L., Khabashesku, V. N., \& Barrera, E. V. (2003). Improving the dispersion and integration of single-walled carbon nanotubes in epoxy composites through functionalization. Nano Letters, 3(8), $1107-1113$

Zhu, J., Peng, H., Rodriguez-Macias, F., Margrave, J. L., Khabashesku, V. N., Imam, A. M., et al. (2004). Reinforcing epoxy polymer composites through covalent integration of functionalized nanotubes. Advanced Functional Materials, 14(7), 643-648.

Zou, W., Du, Z. J., Liu, Y. X., Yang, X., Li, H. Q., \& Zhang, C. (2008). Functionalization of MWNTs using polyacryloyl chloride and the properties of CNT-epoxy matrix nanocomposites. Composites Science and Technology, 68(15), 3259-3264. 